\title{
Polarity reversal of N20 and P23 somatosensory evoked potentials between scalp and depth recordings
}

\author{
Chris W. Vanderzant ${ }^{\text {a }}$, Ahmad A. Beydoun ${ }^{\text {b }}$, Paul A. Domer ${ }^{b}$, Terry W. Hood ${ }^{c}$ \\ and Bassel W. Abou-Khalil ${ }^{\mathrm{d}}$ \\ a Associates in Neurology, 5124 Hollywood Boulevard, Hollywood, FL. (U.S.A.), " Department of Neurology, Unicersity of Michigan, Ann Arbor, \\ MI (U.S.A.). "Minneapolis Neurological Surgeons, Minneapolis, MN (U.S.A.), and d Department of Neurology, Vanderbilt University. Nashville, \\ TN (U.S.A.)
}

(Accepted for publication: 13 November 1990)

\begin{abstract}
Summary From depth and scalp electrodes, we recorded MN-SSEPs of a 33-year-old man with right parietal dysfunction and refractory right temporal seizures. A depth lead with 8 electrodes was implanted deep in each parietal-temporal region. Stimulation and recording parameters followed American EEG Society guidelines. Scalp recordings had well-defined P9. P13-14. N18, N20. and P23 potentials with normal conduction times bilaterally. Depth recordings showed potentials of greater number, voltage. and coherence. P13-14 and N18 were recorded at all depth sites with latencies similar to those at the scalp. N18 had markedly greater voltage and duration near the thalamus, with multiple fast components on its ascending phase. In the deep parietal region there was a positivity corresponding to the scalp $\mathrm{N} 20$ and a negative potential equal in latency to scalp P23. These findings support an origin of P13-14 caudal to the thalamus, multiple thalamic and possibly rostral brain-stem generators for N18, and generation of $\mathrm{N} 20$ and P23 in sensory cortex or subjacent white matter.
\end{abstract}

Key words: Somatosensory evoked potentials; Median nerve; Depth recording; Generator sources: N20; P23

Despite the clinical utility of short-latency median nerve somatosensory evoked potentials (MN-SSEPs), their generator sources are incompletely understood. The origin of even the $\mathrm{N} 20$ potential, one of the principal SSEP components measured in clinical applications, remains controversial after numerous investigations. The N20 is the earliest localized scalp negativity and is restricted to the parietal region contralateral to stimulation, features that suggest an origin in the somatosensory cortex. But some clinico-pathologic correlations (Chiappa et al. 1979; Goldie et al. 1981) imply an N20 generator at the level of the thalamus.

During evaluation of a candidate for epilepsy surgery, we recorded MN-SSEPs from depth electrodes in the parietal and temporal lobes and compared them to the corresponding scalp activity. We found a polarity reversal of the scalp N20 and P23 at deep parietal electrodes, consistent with a cortical rather than thalamic origin of these components.

Correspondence to: Dr. Chris Vanderzant, Associates in Neurology, 5124 Hollywood Blvd., Hollywood, FL 33021 (U.S.A.).

\section{Methods and material}

The subject was a 33-year-old right-handed man undergoing presurgical evaluation of refractory partial seizures of right temporal lobe origin. Seizures began at age 7 years without known etiology. Neurological examination showed right parietal dysfunction, including constructional apraxia. left inferior quadrantanopsia, impaired discriminative sensation on the left side, and decreased alternating motion rate of the left hand. Brain CT showed mild right hemispheric atrophy. Positron emission tomography demonstrated focal hypometabolism in the right temporal-parietal region.

A multi-electrode multiple conductor depth lead was implanted stereotaxically in each parietal-temporal region for depth electroencephalography (Fig. 1). Each lead was constructed of polyurethane tubing with 8 stainless steel electrodes connected by means of fine Teflon-coated stainless steel wire to independent pins mounted in the connector at the lead's proximal end. The electrodes were $2.5 \mathrm{~mm}$ in length and separated by $2.5 \mathrm{~mm}$ of polyurethane tubing.

MN-SSEPs were recorded from the depth electrodes 3 days following their implantation. Four-channel re- 
cordings were obtained on a Grass Model 10 system. Amplifier gain was 24,000 , and amplifier bandpass was $30-3000 \mathrm{~Hz}(-3 \mathrm{~dB})$ with filter roll-off slopes of 12 $\mathrm{dB} /$ octave. The analysis time was $51.2 \mathrm{msec}$ with 1024 data points/channel, giving a dwell time of $50 \mu \mathrm{sec}$. Amplitude resolution of $\mathrm{A} / \mathrm{D}$ conversion was 8 bits.
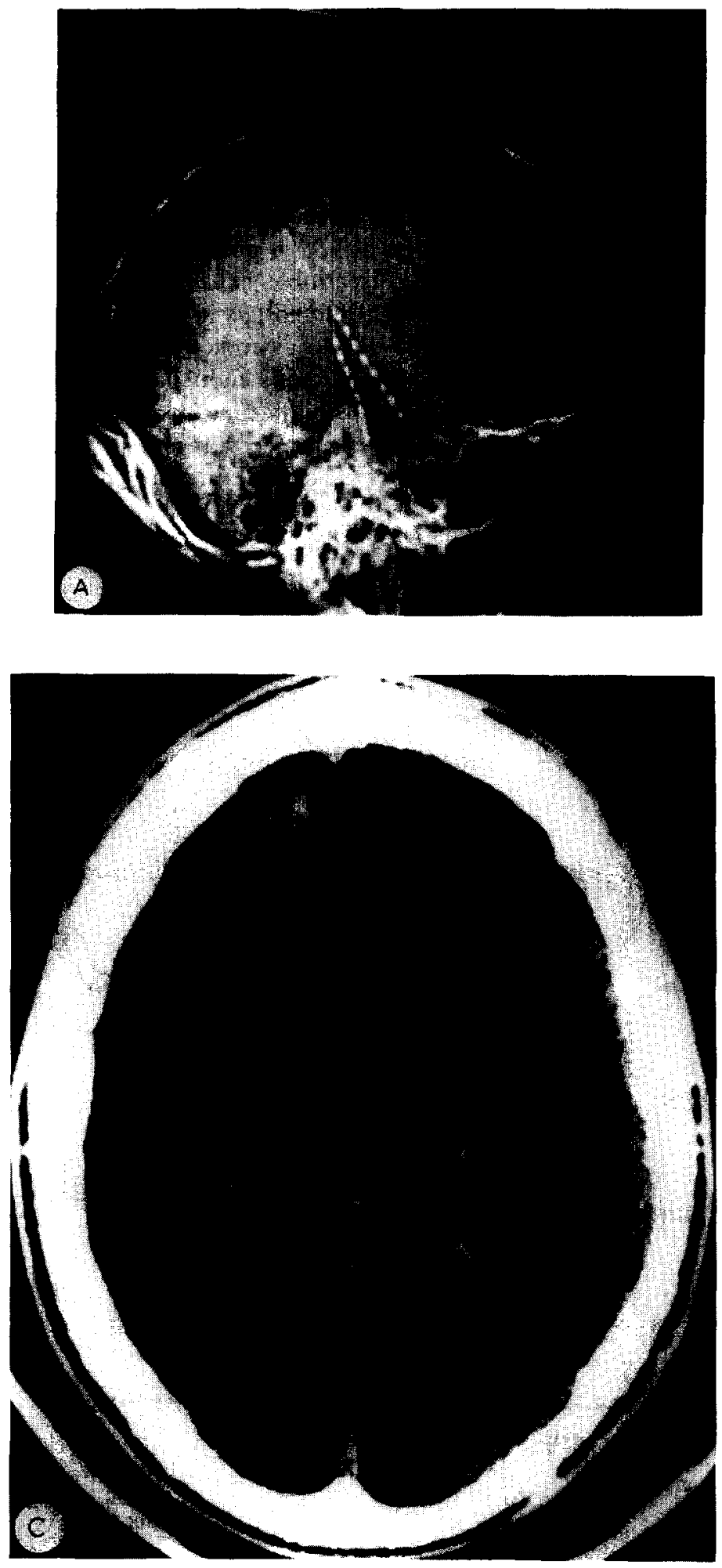

Each average consisted of 1024 samples, repeated at least once for each derivation to assure coherence. Depth electrodes were designated 1 through 8 in sequential order from the distal tip of each depth lead, and referenced to a disk electrode affixed with collodion to the shoulder opposite the stimulated side. MN-SSEPs were

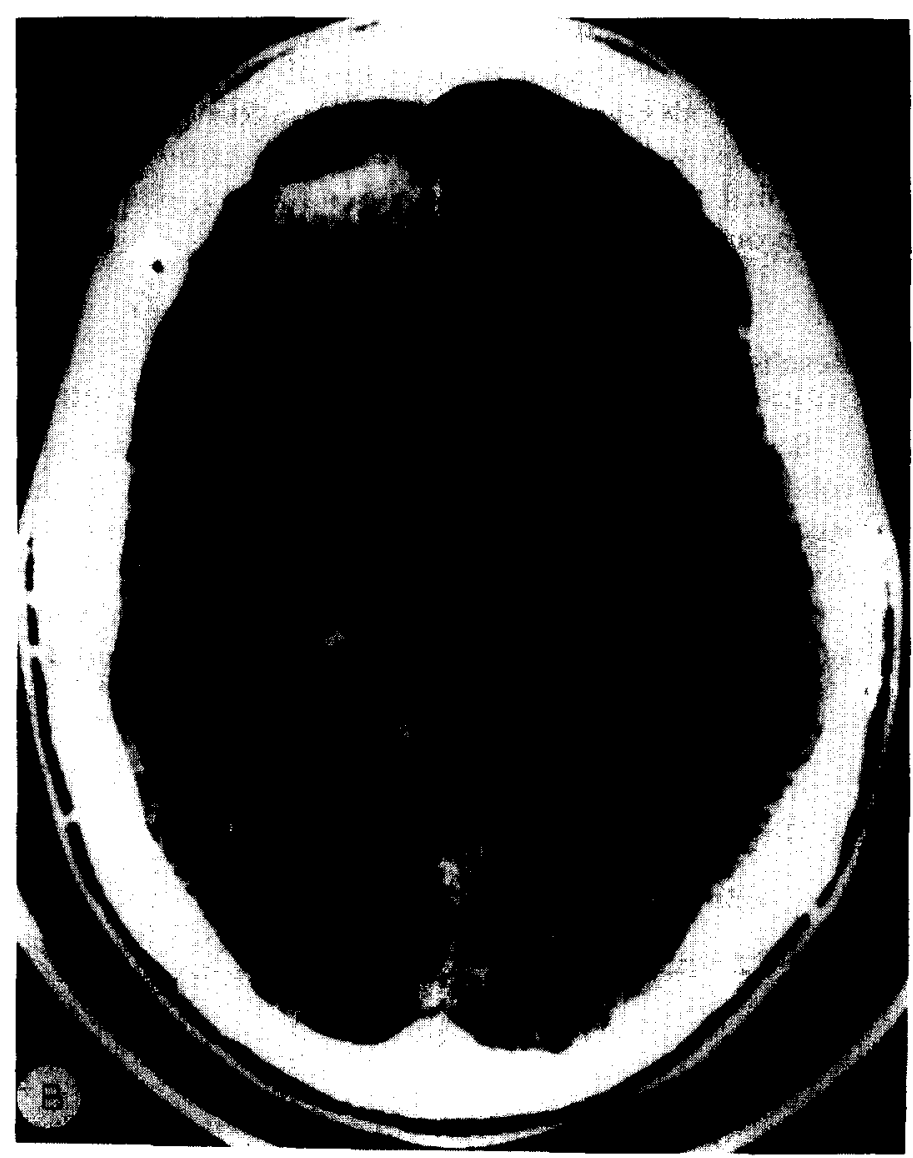

Fig. 1. A: lateral skull film shows position of the depth leads in the parietal and temporal lobes along a dorsoposterior to ventroanterior axis. The 8 electrodes on each lead are discretely visible on plain $X$-ray but not distinguishable from other lead components on CT. B: axial CT at the level of the ventral thalamus, showing depth leads in cross-section at the left no. 4 and right no. $S$ electrodes. $C T$ is without contrast infusion, and right hemisphere is displayed on left side. $\mathrm{C}$ : axial CT at the level of the dorsal thalamus, in the highest plane where depth electrodes (left no. 7 and right no. 8) are situated bilaterally. 
also recorded from scalp, cervical, and Erb's point (EP) electrodes attached with collodion, using the same technique and instrumentation as for depth studies, and in accordance with American EEG Society guidelines (1984). Electrode impedances were maintained below $5000 \Omega$.

The stimulus was a $200 \mu \mathrm{sec}$ square wave generated by a constant current stimulator at a rate of $5.1 \mathrm{~Hz}$. Each wrist was stimulated independently at an intensity sufficient to produce a vigorous thumb twitch. Stimulating electrodes were standard EEG disks with impedances below $10 \mathrm{k} \Omega$, placed with the cathode $2 \mathrm{~cm}$ proximal to the anode. The ground was a plate electrode on the volar forearm.

\section{Results}

Scalp recordings demonstrated good definition and coherence of all potentials on stimulation of either median nerve (Fig. 2). All peak latencies and conduction times were within normal limits (Table I).

Depth recordings showed potentials of greater voltage and complexity with a high degree of reproducibil-
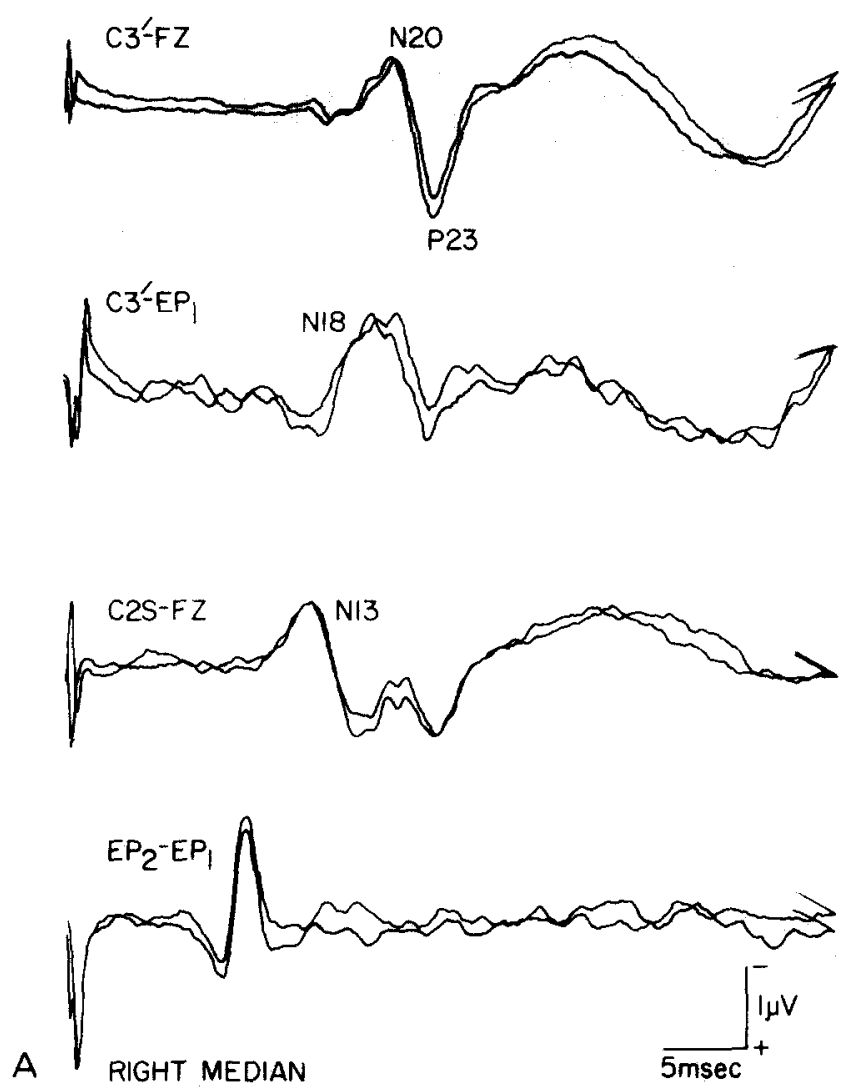

ity (Fig. 3). Potentials similar in latency and polarity to the scalp-recorded P13-14 and N18 were present in all 16 depth derivations. N18 had markedly greater voltage, duration, and complexity at electrodes closest to the thalamus (electrodes 5 and 6). Numerous fast components appeared on the ascending phase of N18 in these derivations. The most dorsal electrodes (left no. 6, and nos. 7 and 8 bilaterally) were situated in or near the deep parietal region on each side. In these derivations, there were 2 potentials that immediately followed N18 and were equal in latency but opposite in polarity to the scalp-recorded N20 and P23 (Fig. 4). Voltage and distribution of these ' $\mathrm{P} 20-\mathrm{N} 23$ ' depth potentials were greater in the left parietal recordings. In right hemisphere depth and scalp recordings, the wave forms following N18 corresponded less clearly, although polarity reversal of the $\mathrm{N} 20$ potential was discernible. The apparent attenuation of ' $\mathrm{P} 20$ ' and ' $\mathrm{N} 23$ ' potentials in right parietal depth recordings may be due to asymmetric placement of the leads. However, the patient's right parietal dysfunction does suggest the possibility that this interhemispheric asymmetry in the depth recordings represents an abnormality that is not detectable in scalp recordings.
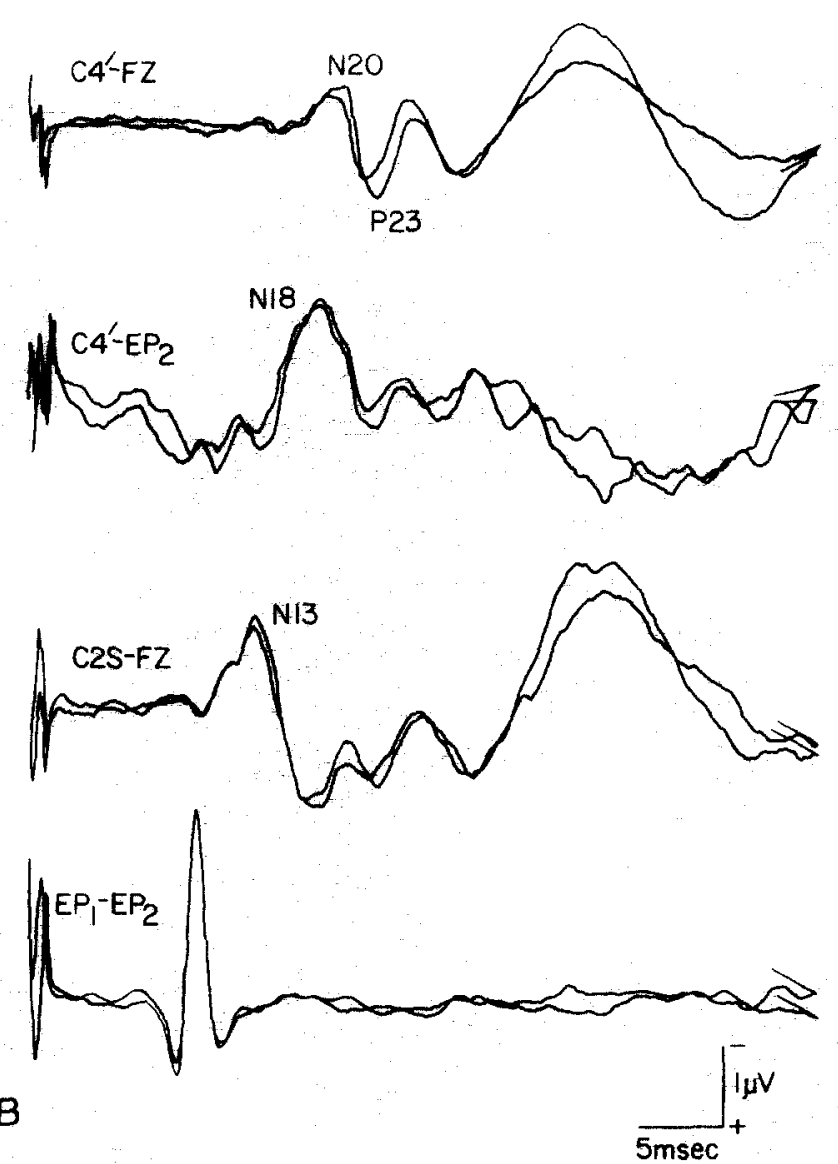

Fig. 2. Scalp SSEP recordings on right (A) and left (B) median nerve stimulation. 
TABLE I

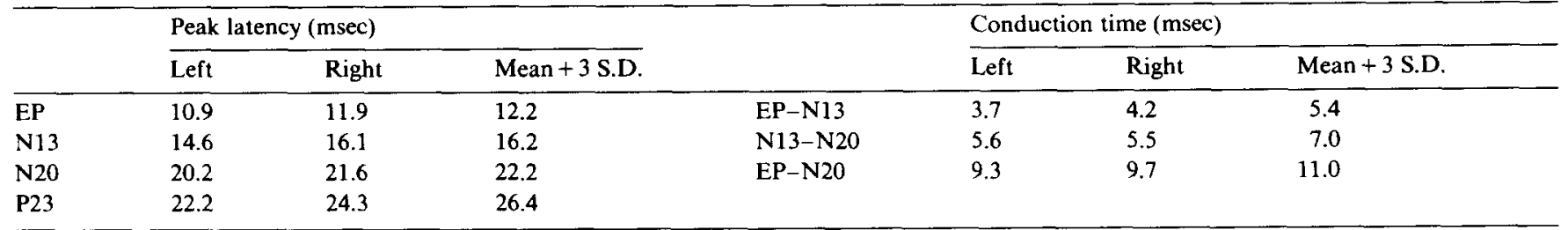

\section{Discussion}

With non-cephalic reference, in the first $18 \mathrm{msec}$ following median nerve stimulation at the wrist in normal adults, similar wave forms are recorded from electrodes placed widely over the scalp (Desmedt and Cheron 1981b; Emerson and Pedley 1984). These consist of P9, P11, P13-14, and N18. Two wave forms, N20
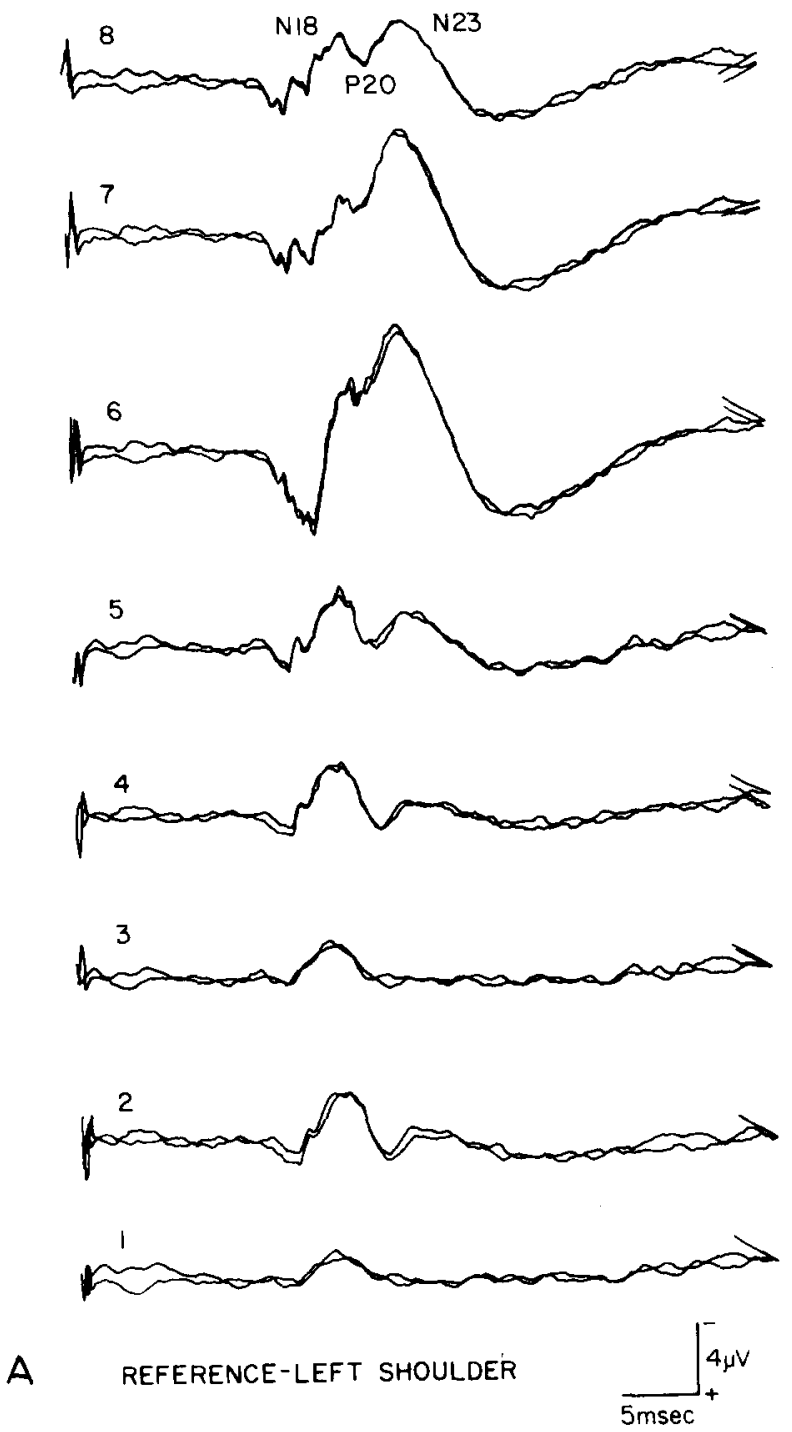

and P23, can only be recorded from the parietal area contralateral to the stimulated side.

The onset of $\mathrm{P} 9$ precedes the potential recorded at Erb's point and represents a stationary far-field potential arising as the afferent volley reaches a site under the lateral part of the clavicle (Cracco and Cracco 1976; Desmedt et al. 1983). The P11 latency corresponds to that of N11 recorded over the posterior aspect of the
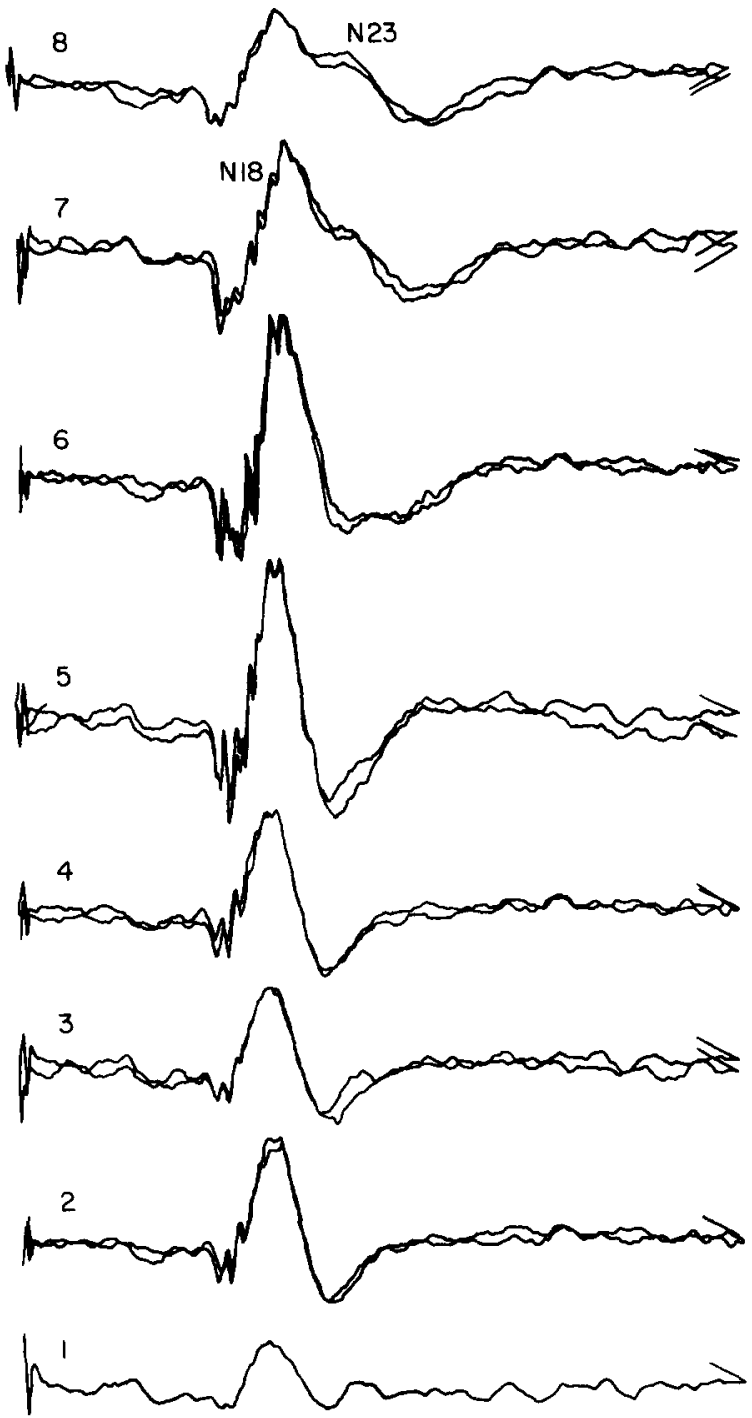

B REFERENCE-RIGHT SHOULDER

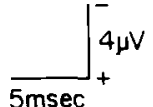

Fig. 3. Depth SSEP recordings: (A) left cerebral hemisphere on right median nerve stimulation, and (B) right cerebral hemisphere on left median nerve stimulation. 


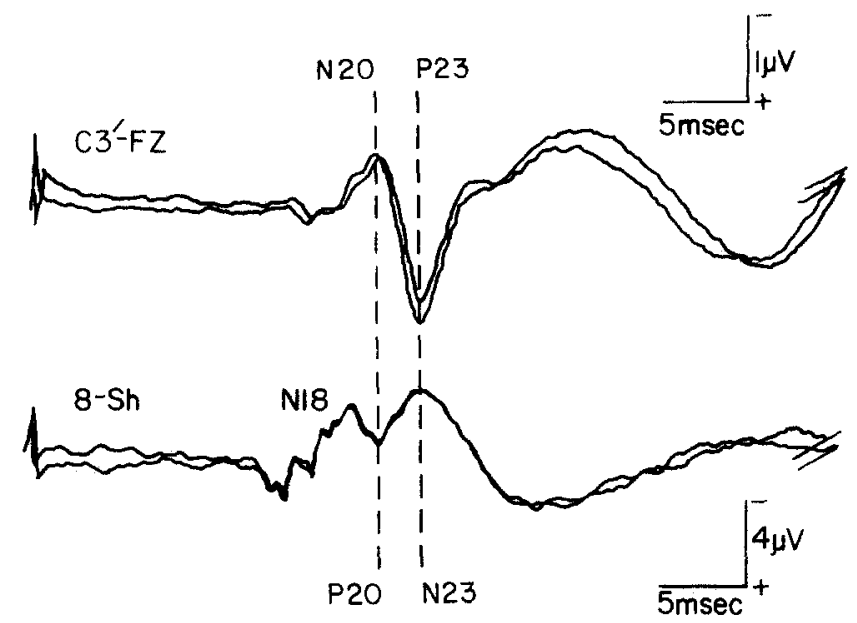

Fig. 4. Comparison of post-N18 components of scalp and depth SSEPs. Left cerebral hemisphere recordings during right median nerve stimulation.

neck (at levels $\mathrm{C} 6-\mathrm{C}$ ), and is believed to be a stationary far-field potential reflecting entry of the afferent volley into the spinal cord (Desmedt and Cheron 1980 , 1981a; Hashimoto 1984). Following P11, scalp electrodes record another positive potential, P13-14. In our study, the P13-14 demonstrated far-field properties in both scalp and depth recordings, even in recordings from electrodes near the thalamus, consistent with a brain-stem generator source. This localization agrees with the findings of other investigators. Intracranial recordings (Lueders et al. 1983a; Hashimoto 1984; Suzuki and Mayanagi 1984), persistence of P13-14 in patients with thalamic lesions (Nakanishi et al. 1978; Anziska and Cracco 1980, 1981; Mauguière et al. 1983b), and calculations based on the latency between passage of the afferent volley past Erb's point and its arrival at the sensory cortex (Desmedt and Cheron 1980, 1981b), all suggest that P13-14 is a far-field stationary potential reflecting the afferent volley in the medial lemniscus.

Following P13-14, the prominent N18 also has a wide scalp distribution. On the basis of thalamic recordings and absence of this potential in patients with thalamic lesions, some investigators have concluded that N18 reflects activity within the thalamus or thalamocortical projection fibers (Celesia 1979; Desmedt and Cheron 1981b). But in other patients with thalamic lesions, N18 was preserved with loss of subsequent wave forms, suggesting generators caudal to the thalamus (Mauguière et al. 1983b; Emerson and Pedley 1984). Our study suggests that N18 is generated predominantly at the thalamus. We found N18 to have markedly greater voltage, duration, and complexity at electrodes closest to the thalamus. The polyphasic appearance of N18 when recorded near the thalamus, with numerous fast components appearing on its ascending phase, suggests that $\mathrm{N} 18$ is a composite wave form representing the summated potentials of multiple generators in the thalamus and adjacent structures. Its long duration (up to $19 \mathrm{msec}$ ) suggests that it represents postsynaptic rather than axonal activities (Mauguière et al. 1983b; Hashimoto 1984).

The earliest localized scalp activity is the negative potential $\mathrm{N} 20$, followed by a positivity, $\mathrm{P} 23$, recorded from the parietal area contralateral to the side of median nerve stimulation. Many studies suggest that N20 and P23 are cortical potentials, based on their near-field properties and their disappearance with certain cortical lesions (Hume and Cant 1978; Desmedt and Cheron 1981b; Mauguière et al. 1983a; Hashimoto 1984). However, some patients with cortical lesions have been described who had a preserved N20 but absent P23, suggesting a more caudal origin of N20 in the thalamus (Chiappa et al. 1979; Goldie et al. 1981). These authors argue that most studies have ignored the retrograde degeneration of primary thalamic nuclei that occurs within 6-12 weeks following a cortical insult. Our recordings suggest that $\mathrm{N} 20$ and $\mathrm{P} 23$ both originate in the sensory cortex or subjacent thalamocortical projection fibers. A cortical or near-cortical origin of both potentials is strongly suggested by the simultaneous occurrence of scalp and deep parietal potentials of opposite polarity. In accordance with a vertical dipole model, their generators must lie somewhere between the cortical surface and the plane of the depth electrodes. Our findings are not consistent with a thalamic origin for $\mathrm{N} 20$, as no wave form of equivalent latency and polarity was recorded at depth electrodes lateral or slightly dorsal to the thalamus. Of interest is Fig. 2 in the report by Hashimoto (1984), which also shows an apparent phase reversal of $\mathrm{N} 20$ and $\mathrm{P} 23$ between the scalp and subcortical white matter, although it is less distinct than in our case.

A vertical orientation of the dipoles describing $N 20$ and $\mathrm{P} 23$ activity has further implications. The somatosensory potentials recorded anterior to the central sulcus, P22 and N24, could not represent phase reversals of $\mathrm{N} 20$ and $\mathrm{P} 23$, as this would involve horizontal rather than vertical dipoles. Other studies also suggest that P22 and N24 are independent potentials arising from separate thalamocortical fibers to the frontal lobes (Desmedt and Cheron 1981b; Lueders et al. 1983b). The absence of $\mathrm{N} 20$ and $\mathrm{P} 23$ with preservation of P22 and $\mathrm{N} 24$ in patients with parietal lesions, and the absence of P22 and N24 with preservation of N20 and P23 in patients with frontal lobe lesions, also support this conclusion (Mauguière et al. 1983a).

\section{References}

American Electroencephalographic Society. Guidelines for clinical evoked potential studies. J. Clin. Neurophysiol., 1984, 1: 3-53. 
Anziska, B. and Cracco, R.Q. Short latency somatosensory evoked potentials: studies in patients with focal neurological disease. Electroenceph. clin. Neurophysiol., 1980, 49: 227-239.

Anziska, B. and Cracco, R.Q. Short latency SEPs to median nerve stimulation: comparison of recording methods and origin of components. Electroenceph. clin. Neurophysiol., 1981, 52: 531-539.

Celesia, G.G. Somatosensory evoked potentials recorded directly from human thalamus and SmI cortical area. Arch. Neurol., 1979, 36: 399-405.

Chiappa, K.H., Young, R.R. and Goldie, W.D. Origins of the components of human short-latency somatosensory evoked responses (SER). Neurology, 1979, 29: 598

Cracco, R.K. and Cracco, J.B. Somatosensory evoked potentials in man: far-field potentials. Electroenceph. clin. Neurophysiol., 1976, 41: $460-466$.

Desmedt, J.E. and Cheron, C. Central somatosensory conduction in man: neural generators and interpeak latencies of the far-field components recorded from neck and right or left scalp and earlobes. Electroenceph. clin. Neurophysiol., 1980, 50: 382-403.

Desmedt, J.E. and Cheron, G. Prevertebral (oesophageal) recording of subcortical somatosensory evoked potentials in man: the spinal P13 component and the dual nature of the spinal generators. Electroenceph. clin. Neurophysiol., 1981a, 52: 257-275.

Desmedt, J.E. and Cheron, G. Non-cephalic reference recording of early somatosensory potentials to finger stimulation in adult or aging normal man: differentiation of widespread N18 and contralateral N20 from the prerolandic P22 and N30 components. Electroenceph. clin. Neurophysiol., 1981 b, 52: 553-570.

Desmedt, J.E., Nguyen, T.H. and Carmeliet, J. Unexpected latency shifts of the stationary $\mathbf{P 9}$ somatosensory evoked potential far field with changes in shoulder position. Electroenceph. clin. Neurophysiol., 1983, 56: 628-634.

Emerson, R.G. and Pedley, T.A. Generator sources of median somatosensory evoked potentials. J. Clin. Neurophysiol., 1984, 1: 203-218.

Goldie, W.D., Chiappa, K.H., Young, R.R. and Brooks, E.B. Brainstem auditory and short-latency somatosensory evoked responses in brain death. Neurology, 1981, 31: 248-256.

Hashimoto, I. Somatosensory evoked potentials from the human brain-stem: origins of short latency potentials. Electroenceph. clin. Neurophysiol, 1984, 57: 221-227.

Hume, A.L. and Cant, B.R. Conduction time in central somatosensory pathways in man. Electroenceph. clin. Neurophysiol., 1978, 45: $361-375$.

Lueders, H., Lesser, R.P., Hahn, J., Little, J. and Klem, G. Subcortical somatosensory evoked potentials to median nerve stimulation. Brain, 1983a, 106: 341-372.

Lueders, H., Lesser, R.P., Hahn, J., Dinner, D.S. and Klem, G. Cortical somatosensory evoked potentials in response to hand stimulation. J. Neurosurg., 1983b, 58: 885-894.

Mauguière, F., Desmedt, J.E. and Courjon, J. Astereognosis and dissociated loss of frontal or parietal components of somatosensory evoked potentials in hemispheric lesions. Brain, 1983a 106: 271-311.

Mauguière, F., Desmedt, J.E. and Courjon. J. Neural generators of N18 and P14 far-field somatosensory evoked potentials studied in patients with lesion of thalamus or thalamo-cortical radiations. Electroenceph. clin. Neurophysiol., 1983b, 56: 283-292.

Nakanishi, T., Shimada, Y., Sakuta, M. and Toyokura, Y. The initial positive component of the scalp-recorded somatosensory evoked potential in normal subjects and in patients with neurological disorders. Electroenceph. clin. Neurophysiol., 1978, 45: 26-34.

Suzuki, I. and Mayanagi, Y. Intracranial recording of short latency somatosensory evoked potentials in man: identification of origin of each component. Electroenceph. clin. Neurophysiol., 1984, 59 . 286-296. 